\title{
Effects of oral administration of the competitive $N$-methyl-D-aspartate antagonist, CGP 40116, on passive avoidance, spatial learning, and neuromotor abilities in mice
}

\author{
Udi Hauben, ${ }^{1}$ Rudi D’Hooge, ${ }^{1}$ Eric Soetens ${ }^{2}$ and Peter P. De Deyn ${ }^{1 *}$ \\ ${ }^{1}$ Laboratory of Neurochemistry and Behaviour, Born-Bunge Foundation, and Department of Neurology- \\ Memory Clinic, Middelheim General Hospital, University of Antwerp, Antwerp, Belgium; and \\ ${ }^{2}$ Cognitive and Physiological Psychology, Free University of Brussels (VUB), Brussels, Belgium
}

[Received 6 October 1998; Revised 5 January 1999; Accepted 5 January 1999]

\begin{abstract}
The effects were investigated of the potent competitive $\mathbf{N}$-methyl-D-aspartate (NMDA) receptor antagonist CGP 40116 [D-(E)-2-amino-4-methyl-5-phosphono-3-pentenoic acid] on the performance of mice in water maze and passive avoidance tasks, and in wire suspension, rotarod, and cage activity tests. The drug was administered per os (p.o.) in its anticonvulsant dose range. CGP 40116 dose-dependently impaired passive avoidance learning when given before, but not when given after training. The antagonist $(5,10$, and $20 \mathrm{mg} / \mathrm{kg}$, administered $4 \mathrm{~h}$ before each training session) dose-dependently affected water maze acquisition, and impaired retention test performance in both hidden- and visible-platform water maze tasks. In addition, the drug dose-dependently decreased swimming speed during water maze acquisition. Repeated administration of CGP 40116 (20 mg/kg, p.o.) persistently decreased cage activity and wire suspension test performance, whereas motor coordination and equilibrium on the rotarod apparatus remained unimpaired. In our administration protocol, no tolerance was found to the effects of the drug on passive avoidance learning and neuromotor abilities. The parallel effects of CGP 40116 on memory and motor performance are discussed, and it was concluded that the antagonist impairs neuromotor abilities and also induces memory impairments which cannot be entirely reduced to motor interference. (c) 1999 Elsevier Science Inc.
\end{abstract}

KEY WORDS: Competitive NMDA antagonist, CGP 40116, Oral administration, Spatial learning, Passive avoidance, Neuromotor performance.

\section{INTRODUCTION}

$N$-Methyl-D-aspartate (NMDA)-type excitatory amino acid (EAA) receptors have been included in a large number of physiological and pathophysiological processes [8]. Although NMDA antagonists impair performance on different learning tasks, spatial learning processes appear to be particularly vulnerable to NMDA receptor blockade $[4,5,12,28,35,36]$. However, the possibility that the apparent learning impairments are due to other adverse effects of the drug on attention, motivation, or sensory-motor control was not ignored by many authors [20,22,31,50]. More recent studies indeed describe motor impairments caused by systemic administration of competitive and non-competitive NMDA antagonists $[1,6]$. The effects of NMDA antagonists on neuromotor abilities might interfere with the acquisition or retrieval phase of learning tasks, resulting in decreased performance not caused by memory impairment.

The compound used in this study, CGP 40116, is the active D-enantiomer of the competitive NMDA antagonist, 2-amino-4methyl-5-phosphono-3-pentenoic acid (CGP 37849, 4-methylAPPA), and the most potent NMDA receptor ligand presently available. The compound acts selectively at the transmitter recognition site of the NMDA receptor with little or no activity at other receptor binding sites $[13,16,43,47]$. The antagonist was shown to have anticonvulsant activity in several rodent and primate models of epilepsy $[7,14,17,19,21,48]$, to be efficacious in a rat model of depression [42], and to protect against different types of experimentally induced neuronal damage [18,27,38-41,45-47]. Schmutz et al. [47] found that ataxia, muscular hypotonia, and motor incoordination occurred at oral doses well above the anticonvulsant values, but this was later contradicted by studies showing motor impairments in mice within the anticonvulsant dose range [19,48]. Ylinen et al. [51] found that CGP 37849 and its carboxyethyl ester CGP 39551, administered intraperitoneally, protect rats against seizures at doses not impairing spatial learning and swimming speed in the Morris-type water maze. However, their conclusions were based on acquisition trials only, without performance of retention tests, and without any additional behavioural information.

In this study, we have assessed the behavioural effects of orally applied CGP 40116 in its anticonvulsant dose range. With the tests used, we have studied the effect of the compound on neuromotor

* Address for correspondence: Peter P. De Deyn, Laboratory of Neurochemistry and Behaviour, Born-Bunge Foundation, University of Antwerp, Universiteitsplein 1, B-2610 Wilrijk, Belgium. Fax: +32-3-8202618. 
abilities as well as its effect on memory performance. We have tested the compound's effect on passive avoidance retention when administered before or after the acquisition trial, and in animals which had received previous treatment with the antagonist.

The dose-dependent effects on spatial learning were examined in the Morris-type water maze. Both in the hidden-platform and the simplified visible-platform condition of the task, the effects of the compound on the spatial component of the task were examined using no-platform retention tests (probe trials). Finally, we tested the effects of the compound on neuromotor performance in cage activity, wire suspension and rotarod tests, while applying the same drug-administration protocol as in the water maze experiment.

\section{MATERIALS AND METHODS}

\section{Animals and Drug Administration}

Seven-week-old male C57BL/6J mice (20-25 g) were used. The mice were housed in groups of eight under standard laboratory conditions (food and water ad libitum; room temperature of $20-$ $22^{\circ} \mathrm{C}$, and approximate humidity of $55 \% ; 12: 12$-h light-dark cycle: $0800 \mathrm{~h}$, lights on; $2000 \mathrm{~h}$, lights off). For some of the experiments, animals were put on reversed light-dark cycle (2000 $\mathrm{h}$, lights on; $0800 \mathrm{~h}$, lights off). Different groups of mice were used for the passive avoidance and water maze protocols, and neuromotor assessment tests. The same animals were never subjected to different testing procedures as prior handling and/or drug treatment may influence behavioural results.

The competitive NMDA antagonist CGP 40116, D-(E)-2-amino-4-methyl-5-phosphono-3-pentenoic-acid, was kindly provided by Dr. M. Geelhand (Novartis Belgium). The compound was dissolved in distilled water, and administered orally using metal feeding cannulae with plastic protection tip (UNO, Zevenaar, The Netherlands). In experiments with four treatment groups, a group treated with sham injections of distilled water and three drugtreated groups $(5,10$, and $20 \mathrm{mg} / \mathrm{kg})$ were considered; in the other experiments, only the highest dose of CGP $40116(20 \mathrm{mg} / \mathrm{kg})$ was applied.

\section{Passive Avoidance Learning}

Mice were used after 3 days of reversed light-dark cycle. Passive avoidance learning was assessed using a step-through procedure, consisting of a single avoidance training trial (always performed between $1300 \mathrm{~h}$ and $1700 \mathrm{~h}$ ), $72 \mathrm{~h}$ later followed by a test (retention) trial. For training, mice were placed in the small $\left(5 \times 9 \mathrm{~cm}^{2}\right)$ brightly lit compartment of the box. After $5 \mathrm{~s}$, the sliding door was opened that led to the big $\left(20 \times 30 \mathrm{~cm}^{2}\right)$ dark compartment of the box (all animals entered within $30 \mathrm{~s}$ ). Upon entrance of the dark compartment, the door was closed and the mice received a slight electric foot shock (Coulbourn Instruments Small Animal Shocker, Allentown, PA, USA; 0.2 mA, 1-2 s). Upon shocker activation, the dark compartment cover was lifted and the response of the mice to the electric foot shock was confirmed. After $72 \mathrm{~h}$, the mice were placed once more in the small compartment for their test trial, and latency to enter the dark compartment was noted up to a maximum of $300 \mathrm{~s}$.

To test the effect of CGP 40116 on avoidance learning, mice were orally injected with CGP $40116(0,5,10$, or $20 \mathrm{mg} / \mathrm{kg} ; 10-15$ animals per treatment group) $4 \mathrm{~h}$ before training (latency for maximal anticonvulsant effect according to [47]). To test drug effect on passive avoidance memory maintenance, an additional group of mice $(n=12)$ was injected with $20 \mathrm{mg} / \mathrm{kg}$ of the drug immediately after training. To assess the effect of prior treatment, mice received 8 oral injections of $20 \mathrm{mg} / \mathrm{kg}$ CGP $40116(n=8)$ or water $(n=7)$, according to the same daily drug administration protocol applied for the spatial learning task. After this pre-treatment, mice were injected once more with water or CGP 40116 (20 $\mathrm{mg} / \mathrm{kg}$ ), respectively, $4 \mathrm{~h}$ prior to training, and tested $72 \mathrm{~h}$ later.

\section{Spatial Learning}

For the assessment of spatial learning, we used a Morris-type water maze consisting of a circular grey plastic pool $(150 \mathrm{~cm}$ in diameter, $30 \mathrm{~cm}$ high) filled with water made opaque by non-toxic white paint, and maintained at $26^{\circ} \mathrm{C}$. A round Perspex platform $(15$ $\mathrm{cm}$ diameter) was placed inside the pool at the centre of the north-east quadrant. The platform was placed $1 \mathrm{~cm}$ below the water surface in the hidden-platform condition, but was made clearly visible with a black pole, in the visible-platform condition. The protocol consisted of two consecutive sessions of four daily acquisition trial blocks followed by a 3-day rest period (allowing $96 \mathrm{~h}$ without drug application), and a single (retention) probe trial (also indicated in Fig. 2 as P1 and P2). Acquisition trial blocks were performed daily, and consisted of four acquisition trials (15-min intertrial interval) during which the animals were placed in the water facing the side, in random order at one of the four starting positions (north, south, east, and west). If an animal could not find the platform within the maximum swimming time of $120 \mathrm{~s}$, it was placed on the platform and had to stay on it for $15 \mathrm{~s}$ before removal, and a maximal escape latency of $120 \mathrm{~s}$ was noted. Probe trials were performed both in the hidden- and visibleplatform condition. During probe trials, mice had to swim for $100 \mathrm{~s}$ in the pool without a platform. Probe trial 1 (P1) was performed 3 days after the fourth acquisition trial block, and probe trial 2 (P2), 3 days after the eighth trial block (also indicated in Fig. 2).

The effect was examined of CGP 40116 treatment on hiddenand visible-platform water maze acquisition. Treatment was administered $4 \mathrm{~h}$ before each acquisition trial block, and consisted of oral injection of distilled water or CGP 40116 solutions in doses of 5,10 , and $20 \mathrm{mg} / \mathrm{kg}$. Groups of 8-12 mice were considered for each dose in the hidden- and visible-platform condition.

\section{Neuromotor Abilities}

Neuromotor ability tests (cage activity, wire suspension, and rotarod) were repeatedly performed on the same group of animals (between $1300 \mathrm{~h}$ and $1700 \mathrm{~h}$ ) using the same drug administration protocol as used for spatial learning assessment (see above). Cage activity was measured according to a technique modified from Crawley and Goodwin [10]. Animals on reversed light-dark cycle, were placed in transparent mouse cages $\left(20 \times 25 \mathrm{~cm}^{2}\right.$ floor area), which were put between three infrared photobeams connected to a microprocessor counter. Activity (expressed as number of beam crossings) was measured for $2 \mathrm{~h}$ in a dimly lit quiet room. For wire suspension test of grip strength and endurance, the front paws of the mouse were placed on a horizontal steel wire $(0.6 \mathrm{~mm}$ thick $)$ suspended at a height of $46 \mathrm{~cm}$ above tabletop. Mice were allowed to drop twice during the 60 -s assessment period before being considered to fail the test. Following the wire suspension test, neuromotor coordination and equilibrium were evaluated on a lab-build rotarod apparatus [15]. Mice were placed on a rotating plastic rod ( $3 \mathrm{~cm}$ thick, $15 \mathrm{~cm}$ high, $12 \mathrm{rpm}$ ) above a glass plate. There were four trials (10-min intertrial interval), and the latency before the mice fell off the rod was recorded with a 120-s cut-off.

Treatment consisted of oral injection of distilled water $(n=7)$ or $20 \mathrm{mg} / \mathrm{kg}$ CGP $40116(n=8)$. Cage activity was measured $2 \mathrm{~h}$ after drug administration; wire suspension and rotarod tests were performed after cage activity testing, $4 \mathrm{~h}$ after drug administration. 


\section{Statistics}

Significance of differences between means were assessed using analysis of variance (ANOVA) and two-tailed Student's $t$-test; differences between proportions were assessed using chi-square analysis and Fisher's exact test. Level of statistical significance was set at $5 \%$. In the passive avoidance experiments, one-way ANOVA was used to assess the effect of treatment (four treatment groups) on step-through latency. In the water maze acquisition experiments, mean escape latency, path length, and swimming velocity (summed per trial block) were analysed using two-way repeated measures ANOVA with treatment (four groups, $d f=3$ ), trial block (eight repeated measures, $d f=7$ ) and interaction $(d f=$ 21 ) as sources of variation. One-factor ANOVA and Student's $t$-tests were used to determine the significance of the effects of treatment on the number of target area entries and time spent in the target (north-east) quadrant during the probe trials. Two-tailed Student's $t$-test was used for post-hoc pairwise comparison of means.

\section{RESULTS}

Effect of Pre-Training and Immediate Post-Training Oral Administration on Passive Avoidance Retention

Figure 1A (left part) shows the effect of p.o. CGP 40116 without pretreatment on step-through latency during training and testing trials. In the water-treated control group, all mice promptly entered the dark compartment during the training trial, whereas none of these animals re-entered during the testing trial, $72 \mathrm{~h}$ later. Latency during training was not influenced by CGP 40116 administration (one-way ANOVA; $p>0.05$ ). However, the compound dose-dependently reduced step-through latency during the testing trials. One-way ANOVA revealed a highly significant effect of the dose of CGP 40116 on step-through latency during testing $[F(3,52)=12.963, p<0.001]$, and pairwise comparison by post-hoc Student's $t$-test indicated significantly decreased latencies in the $10 \mathrm{mg} / \mathrm{kg}$ and $20 \mathrm{mg} / \mathrm{kg}$ groups compared to controls. The drug also dose-dependently decreased the percentage of animals not entering the dark compartment within $300 \mathrm{~s}$, as chi-square analysis indicated a highly significant relationship between the dose and percentage of animals not entering $(p<0.001$; Fig. 1B, left part). Alternatively, when the drug was administered immediately after the training trial, all animals avoided the dark compartment, and no effect of p.o. CGP 40116 on step-through latency was found (one-way ANOVA; $p>0.05$; not shown in figure).

Similar impairment of passive avoidance learning was seen in a group pre-treated with eight $20 \mathrm{mg} / \mathrm{kg}$ CGP 40116 injections (Fig. 1A, B, right part). Six out of eight CGP 40116-treated animals re-entered the dark compartment during the testing trial, whereas seven water-treated animals did not ( $p=0.007$; Fisher's exact test), and step-through latency was significantly longer in the control group than in the CGP 40116-treated group ( $p=0.002$; Student's $t$-test). There was no significant difference in stepthrough latency and percentage of animals not entering between mice with and those without CGP 40116 pre-treatment $(p>0.5$; Student's $t$-test and Fisher exact test, respectively).

\section{Effect on Hidden-Platform Water Maze Acquisition}

The four groups $(0,5,10$, or $20 \mathrm{mg} / \mathrm{kg})$ showed a progressive decline in escape latency (Fig. 2A, only sham injection and highest dose displayed) and path length during the 8 training days. Twoway repeated measures ANOVA revealed a significant overall effect of treatment on escape latency $[F(3,36)=4.545, p=$ 0.008], whereas the interaction between treatment and training day was not significant. Comparison between treatments showed
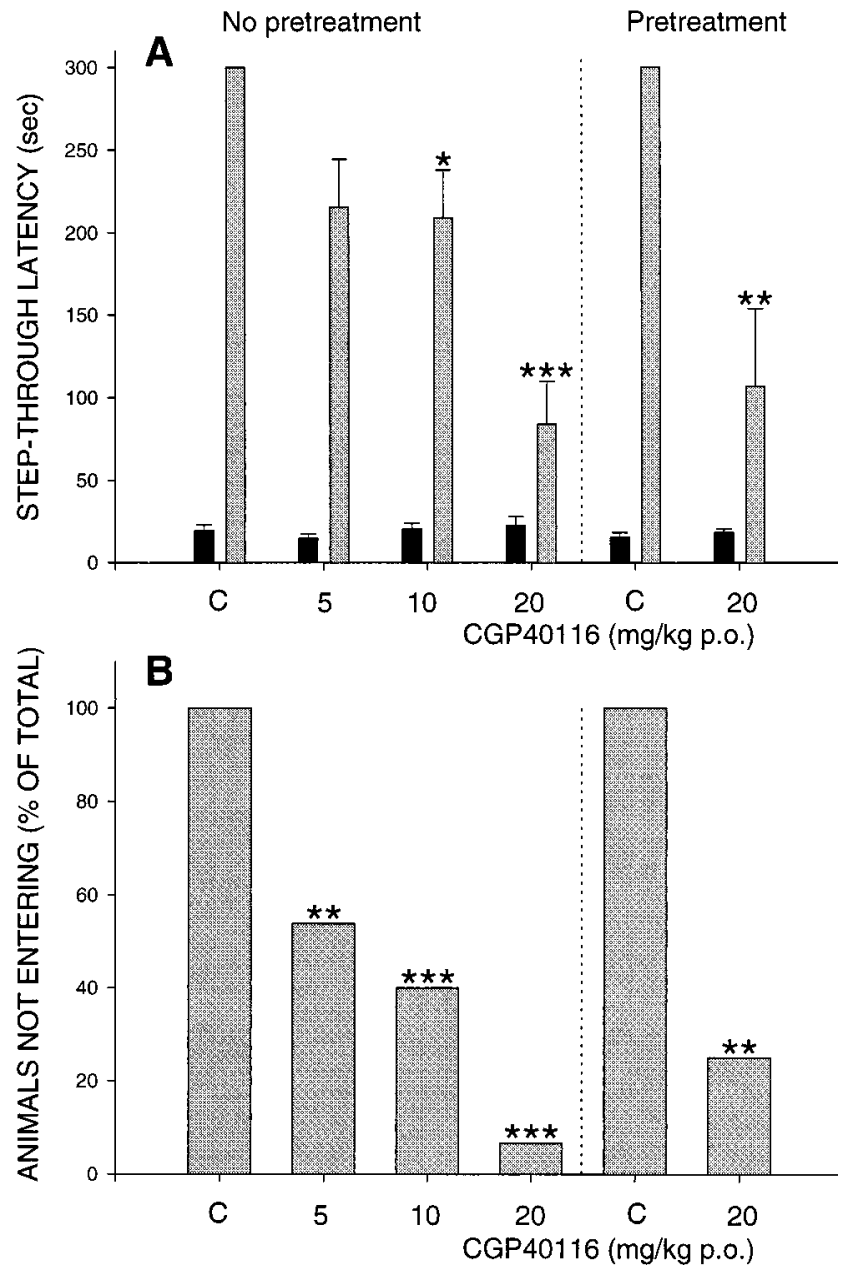

FIG. 1. Effect of $4 \mathrm{~h}$ pre-training oral administration of CGP 40116 on step-through latencies of male C57BL mice in passive avoidance learning (A). Bars depict mean step-through latency (and SEM) during training (black bars) and testing (grey bars) trials in 4 groups of mice $(n=10-15$ per group) receiving either distilled water (control group, C) or CGP 40116 $(5,10$, and $20 \mathrm{mg} / \mathrm{kg}), 4 \mathrm{~h}$ before training. Pre-treatment groups $(n=7-8$ per group) were pre-treated with eight daily injections of water (control group, C) or $20 \mathrm{mg} / \mathrm{kg}$ CGP 40116 . Impairment of passive avoidance performance is evident in the dose-dependent decrease of the step-through latency. The percentage of animals in each experimental group, with and without pre-treatment that did not enter the dark compartment during the testing trial showed the same effect of CGP 40116 treatment (B). ${ }^{*} p<$ $0.05 ; * * p<0.01, * * * p<0.001$ vs. control group (Student's $t$-test or Fisher's exact test). See text for statistical analysis.

that $5 \mathrm{mg} / \mathrm{kg}$ and $10 \mathrm{mg} / \mathrm{kg}$ CGP 40116 did not significantly affect escape latency, whereas mice treated with $20 \mathrm{mg} / \mathrm{kg}$ did show significantly increased escape latencies compared to controls (twoway repeated measures ANOVA, $F(1,20)=21.255, p=0.001$; Fig. 2A). Path length was not significantly different between treatments (not shown in figure).

Swimming velocity was significantly decreased in the CGP 40116-treated animals compared to the sham-injected animals (not shown in figure). Two-way repeated measures ANOVA revealed a significant effect of treatment on swimming speed $[\mathrm{F}(3,36)=$ $11.151, p=0.001]$. Analyzed separately, all three doses of CGP 40116 were shown to have a statistically significant effect on 


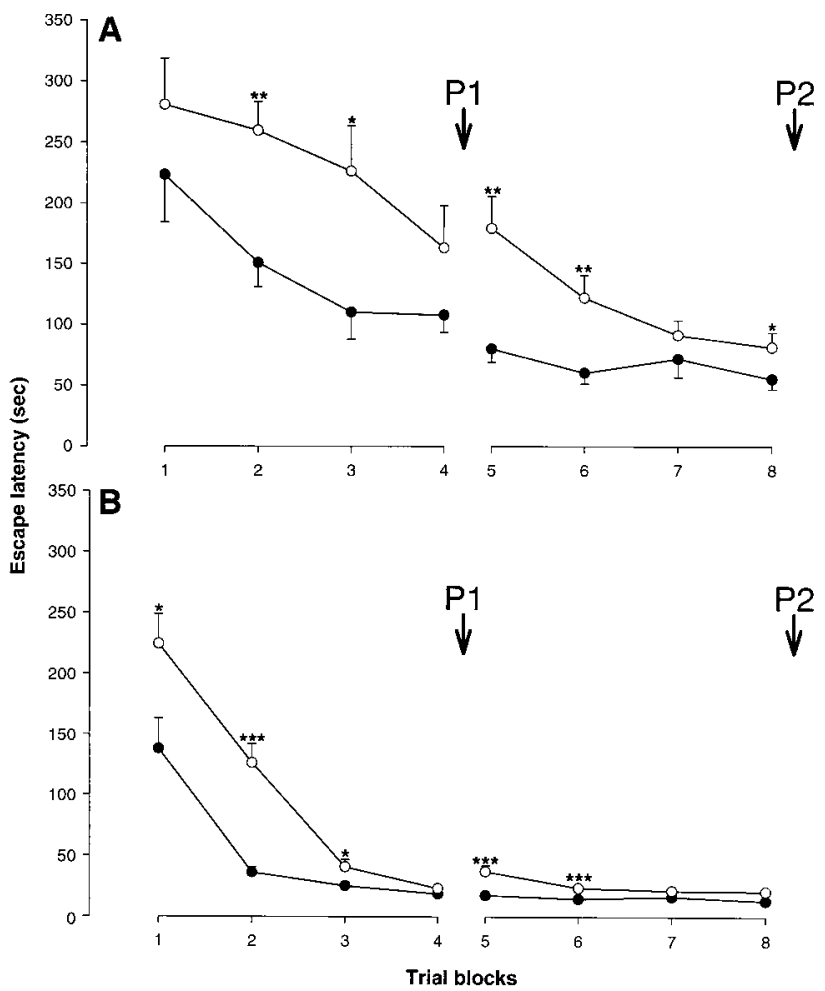

FIG. 2. Mean escape latency (and SEM) during acquisition trials of the hidden- ( $n=8-12$ per group; A) and visible-platform $(n=10$ per group; B) water maze task. Only the highest dose group is shown in the figure. Mice were treated with water (closed symbols) or CGP 40116, $20 \mathrm{mg} / \mathrm{kg}$ (open symbols), $4 \mathrm{~h}$ before each trial block. Although performance improved in all groups as a result of training, escape latency is highly increased in the CGP 40116-treated group, both in the hidden (A) and visible (B) condition. $* p<0.05$; ** $p<0.01$; *** $p<0.001$ vs water-treated group (two-tailed $t$-test). Timing of probe trails 1 and 2 (P1 and $\mathrm{P} 2$, respectively) are indicated with arrows. See text for statistical analysis.

swimming speed $[5 \mathrm{mg} / \mathrm{kg}(p<0.004), 10 \mathrm{mg} / \mathrm{kg}(p<0.001)$ and $20 \mathrm{mg} / \mathrm{kg}(p<0.001)]$. Compared to a mean velocity $( \pm \mathrm{SEM})$ of $21.4 \pm 0.6 \mathrm{~cm} / \mathrm{s}$ in sham-treated animals during the eight acquisition trial blocks, 5, 10, and $20 \mathrm{mg} / \mathrm{kg}$ CGP 40116treated mice showed velocities of $18.4 \pm 0.7,17.2 \pm 0.8$, and $16.3 \pm 0.7 \mathrm{~cm} / \mathrm{s}$, respectively.

\section{Effect on Visible-Platform Water Maze Acquisition}

Two-way repeated measures ANOVA revealed a significant effect of treatment on escape latency in the visible-platform condition $[\mathrm{F}(3,240)=7.042, p=0.001$; Fig. $2 \mathrm{~B}$, only sham injection and highest dose displayed]. The interaction between treatment and training day was significant $[\mathrm{F}(21,240)=2.208$, $p=0.002]$. Path length was not significantly different between treatments, whereas the interaction between treatment and training day did have a significant effect on path length $[\mathrm{F}(21,240)=$ 1.673, $p=0.036]$.

Like in the hidden-platform condition the drug decreased swimming velocity. Two-way repeated measures ANOVA revealed a significant overall effect of treatment on swimming speed $[\mathrm{F}(3,35)=14.666, p=0.001]$. Comparison between treatments showed that doses of $20 \mathrm{mg} / \mathrm{kg}(p<0.001)$ and $10 \mathrm{mg} / \mathrm{kg}$ $(p<0.001)$, but not $5 \mathrm{mg} / \mathrm{kg}(p>0.05)$ had a statistically significant effect on swimming speed. Compared to a mean velocity $( \pm \mathrm{SEM})$ of $23.6 \pm 0.6 \mathrm{~cm} / \mathrm{s}$ in sham-treated animals during the eight acquisition trial blocks, 10 and $20 \mathrm{mg} / \mathrm{kg}$ CGP 40116-treated mice showed velocities of $20.2 \pm 0.6$ and $18.1 \pm 0.7 \mathrm{~cm} / \mathrm{s}$, respectively.

\section{Effect of Administration During Acquisition on Probe Trial Retention}

Probe trials 1 and 2 were performed after the first and the second acquisition session (four acquisition trial blocks), both in the hidden- and visible-platform condition (as indicated in Fig. 2). In contrast to the acquisition trials, there were no significant differences in swimming speed between treatment groups during the probe trials. In the hidden-platform condition, time spent in the different quadrants during Probe 1 indicated a change in spatial search pattern (Fig. 3A; for each of the treatment groups: significant effect of quadrant on the time spent in the different quadrants; one-way ANOVA). However, the results of Probe 1 also demonstrate that treatment with CGP 40116 during the acquisition phase impaired performance during the retrieval phase of the task (Fig. 3A-B). Indeed, while the control group showed a preference to search in the target quadrant, the $20 \mathrm{mg} / \mathrm{kg}$-treated animals spent significantly longer time in the adjacent quadrant compared to the target quadrant (Fig. 3A), and the number of target area entries in the $20 \mathrm{mg} / \mathrm{kg}$ group was significantly lower than in the shamtreated group (Student's $t$-test, $p=0.01$; Fig. 3B).

In the hidden-platform condition Probe 2 , the differences between control and CGP 40116-treated animals became even more obvious (Fig. 3C-D). Time spent in the target quadrant decreased with increasing dose of CGP 40116 (Fig. 3C), and one-way ANOVA showed a significant effect of treatment on time spent in the target quadrant $[\mathrm{F}(3,36)=2.931, p=0.047]$. A significant difference was found between the $20 \mathrm{mg} / \mathrm{kg}$ group and the shamtreated control group (post-hoc Student's $t$-test, $p=0.032$ ), but not between sham-treated and respective 5 and $10 \mathrm{mg} / \mathrm{kg}$ groups. Also in the $20 \mathrm{mg} / \mathrm{kg}$ group, the time spent in the target quadrant during Probe 2 was not significantly longer than the time spent in the other quadrants. Target entries also decreased dose-dependently (Fig. 3D), and one-way ANOVA revealed a significant effect of treatment on target entries $[\mathrm{F}(3,36)=4.842, p=$ 0.006]. Pairwise comparison showed a highly significant difference between the $20 \mathrm{mg} / \mathrm{kg}$-treated animals and the control group ( $p=0.001$; post-hoc Student's $t$-test), but not between shamtreated and respective 5 and $10 \mathrm{mg} / \mathrm{kg}$ groups.

Treatment with CGP 40116 also affected the performance in the visible-platform condition probe trials (Fig. 4). The number of target entries decreased dose-dependently (Fig. 4B), and one-way ANOVA revealed a significant effect of treatment on the average number of target entries during Probe $1[\mathrm{~F}(3,35)=5.64, p=$ $0.003]$. Subsequent pairwise analysis revealed a significant difference in the number of target entries between the control group and the respective $10(p<0.05)$ and $20 \mathrm{mg} / \mathrm{kg}(p<0.01)$ groups. However, there was no effect of CGP 40116 treatment on time spent in the target quadrant during visible-platform condition Probe 2 (Fig. 4C), nor on entries in the target quadrant (Fig. 4D).

It is interesting to note that sham-treated animals showed no significant difference between the number of target entries in visible-platform condition Probe 1 and 2 (Fig. 4 B,D), indicating that no additional increase in spatial accuracy was obtained between the two probe trials. In the hidden-platform condition, on the other hand, control animals did show a significantly higher number of target entries during Probe 2 than during Probe 1 ( $p=0.026$; 


\section{Hidden-platform task, Probe 1}
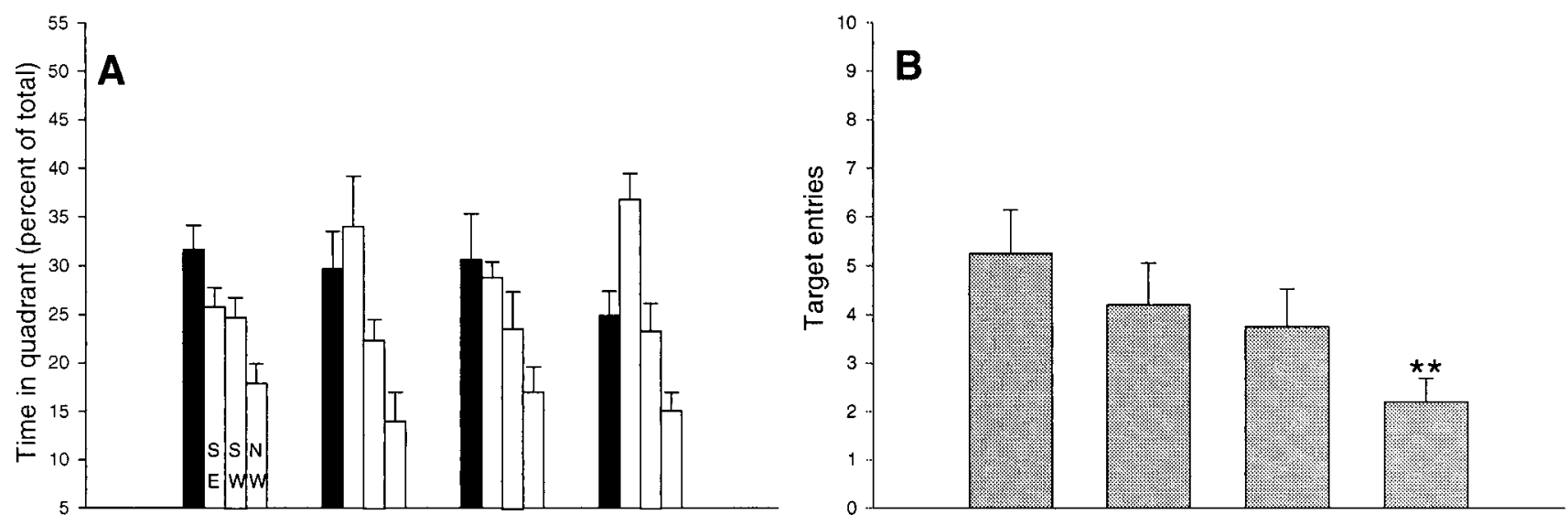

Hidden-platform task, Probe 2
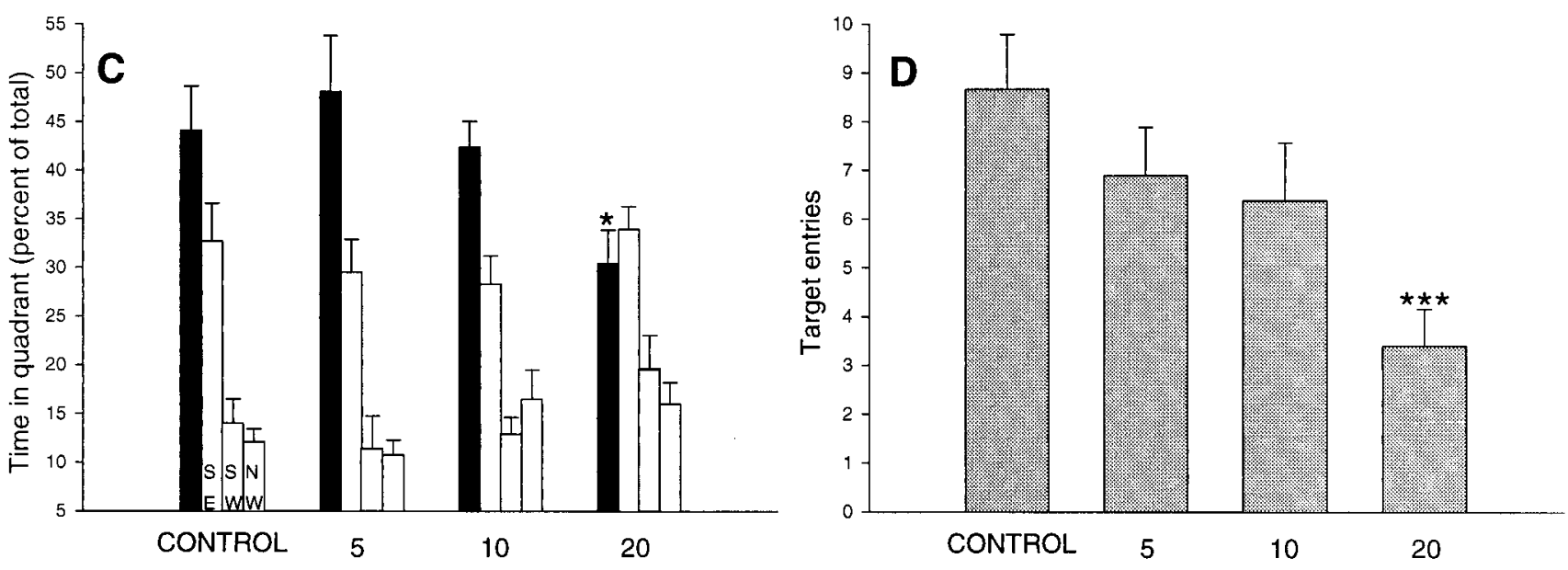

FIG. 3. Average time spent in each quadrant of the pool (A,C) and target area entries (B,D) during two probe trials performed after four (Probe 1, A-B) and eight (Probe 2, C-D) acquisition trial blocks in the hidden-platform maze (acquisition depicted in Fig. 2A). Bars represent the mean percentage of time (and SEM) spent in the target quadrant (north-east, black bar) or south-east (SE), south-west (SW), or north-west (NW) quadrants (white bars: SE, SW, and NW, respectively) in water- (control group, C) and CGP 40116-treated (5, 10 and $20 \mathrm{mg} / \mathrm{kg}$ ) groups. Probe trials were performed after $96 \mathrm{~h}$ without drug application. Effects of CGP 40116 is manifested by decreased spatial accuracy measures in Probe 1 (A,B) and $2(\mathrm{C}, \mathrm{D}) . * p<0.05 ; * * p<0.01$; $* * * p<0.001$ vs. control group (Student's $t$-test). See text for statistical analysis.

Student's $t$-test; Fig. 3 B,D), probably due to a longer learning process in this more severe condition.

\section{Effect on Neuromotor Abilities}

During 8 drug-administration days, CGP 40116-treated animals (20 mg/kg) showed persistently decreased cage activity (Fig. 5). Two-way repeated measures ANOVA revealed a highly significant effect of treatment on cage activity $(p=0.001)$ in an administration schedule parallel to that used in the water maze experiments. The wire suspension test measures muscle strength by examining an animal's ability to grasp a horizontal wire with its forepaws and remain suspended. A proportion of the mice treated with $20 \mathrm{mg} / \mathrm{kg}$ CGP 40116 failed this test, and no indications of improvement were seen during the testing period. All control animals $(n=7)$ were able to perform the task during the 8 testing days, whereas out of eight CGP 40116-treated mice, seven failed the test on day 5 ( $p=0.001$; Fisher's exact test), six on days 2-3 and 6-eight $(p=0.007)$, five on day $1(p=0.026)$, and four on day $4(p=0.077)$. Finally, in the motor coordination and equilibrium rotarod test, animals of both groups could perform this task without apparent difficulties.

\section{DISCUSSION}

This study aimed to investigate the parallel effects of oral administration of the potent competitive NMDA receptor antagonist CGP 40116 on neuromotor and cognitive performance in mice using step-through box, Morris-type water maze and motor assessment protocols. The results of this study are in line with previous findings in suggesting that learning and memory impairments in passive avoidance and water maze tests, following NMDA antag- 


\section{Visible-platform task, Probe 1}
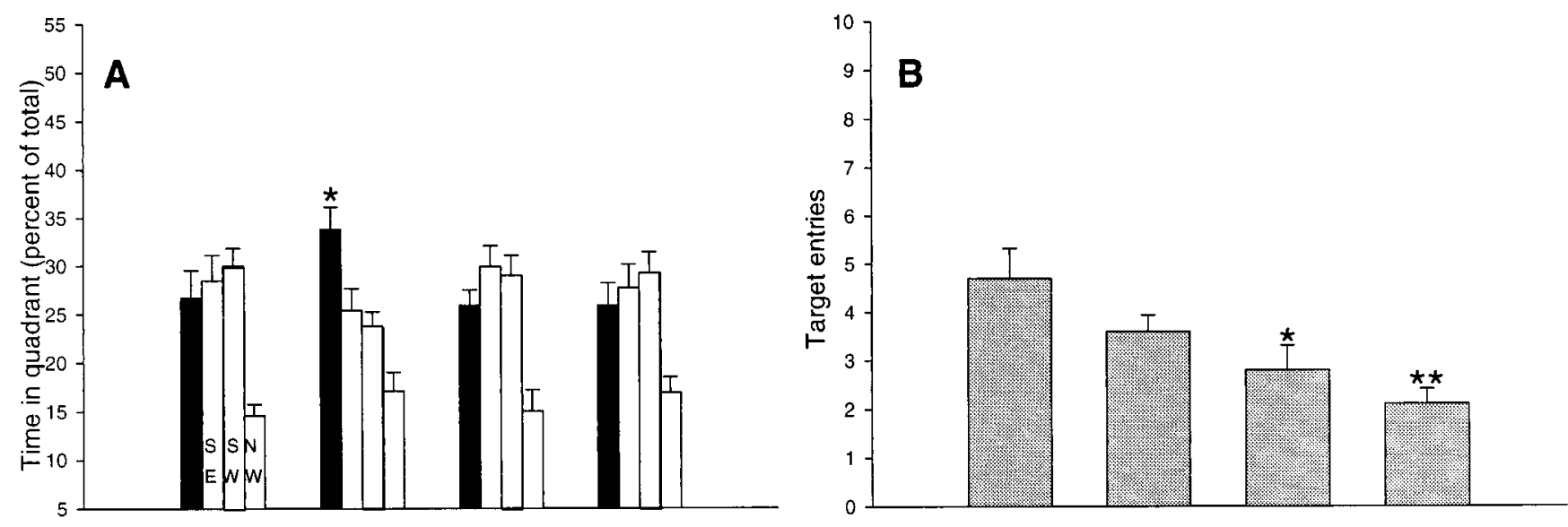

\section{Visible-platform task, Probe 2}
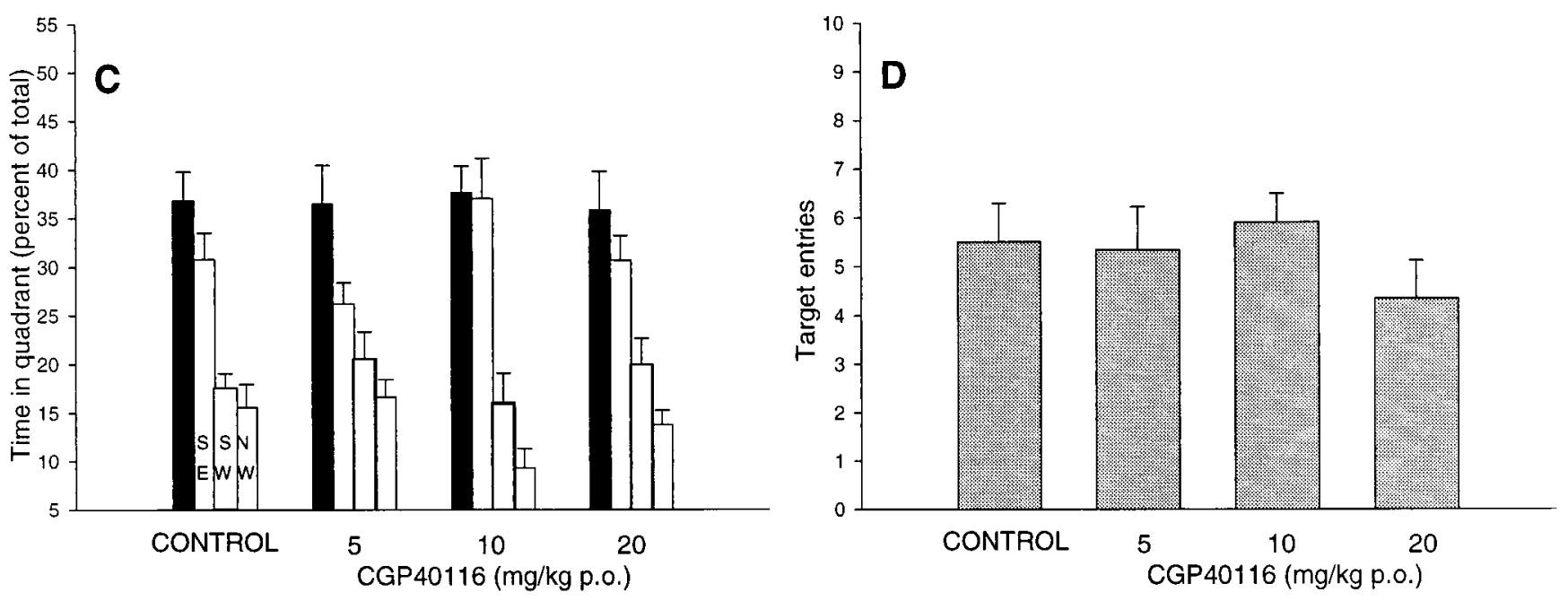

FIG. 4. Average time spent in each quadrant (A,C) and target area entries (B,D) in two probe trials performed after four (Probe 1, A-B) and eight (Probe 2, C-D) acquisition trial blocks in the visible-platform maze (acquisition depicted in Fig. 2B). Bars represent the mean percentage of time (and SEM) spent in the target quadrant (north-east, black bar) or south-east (SE), south-west (SW), or north-west (NW) quadrants (white bars: SE, SW and NW, respectively) in water- (control group, C) and CGP 40116-treated $(5,10$ and $20 \mathrm{mg} / \mathrm{kg}$ ) groups. Probe trials were performed after $96 \mathrm{~h}$ without drug application. Effects of CGP 40116 is manifested by decreased spatial accuracy measures in Probe 1 (A,B) and 2 (C,D). * $p<0.05 ; * * p<0.01 ; * * p<0.001$ vs. control group (Student's $t$-test). See text for statistical analysis.

onist administration, are not entirely reducible to disruption of sensory-motor processes [12,29,36,37].

We have shown that oral administration of CGP 40116 dosedependently impairs the acquisition of the passive avoidance response without affecting maintenance or retrieval of stored information. The compound had similar effects in animals which had been pre-treated with the drug. The effects on acquisition are consistent with reported effects of other competitive and noncompetitive NMDA receptor antagonists [11,30,35,50]. It has been argued that impaired performance on learning tests could be due to the effect of NMDA antagonists on sensory-motor systems. However, Venable and Kelly [50] obtained no evidence that the drugs decreased shock sensitivity, and in fact found a slight but significant reduction in the shock intensity eliciting vocalization in their mice. In our experiments, the animals' response to the shock was confirmed during training, and retention was tested when the animals were not under the influence of the drug. The minimal motor requirements of the step-through paradigm minimize the possible contribution of drug-induced motor impairments, and indeed step-through latency during the training phase of the test was not affected by CGP 40116. Our results suggest that CGP 40116 impairs the performance of this task, and affects memory formation in the dose range that was found for the suppression of maximal electroshock-induced seizures in mice [16].

We found that oral administration of CGP 40116 does impair motor performance in the water maze (reduced swimming speed in both hidden- and visible-platform conditions), but in addition appears to decrease dose-dependently the acquisition rate of spatial information in this task. Interestingly, low doses of CGP 37849 have been shown to facilitate learning and memory [23,32,33]. 


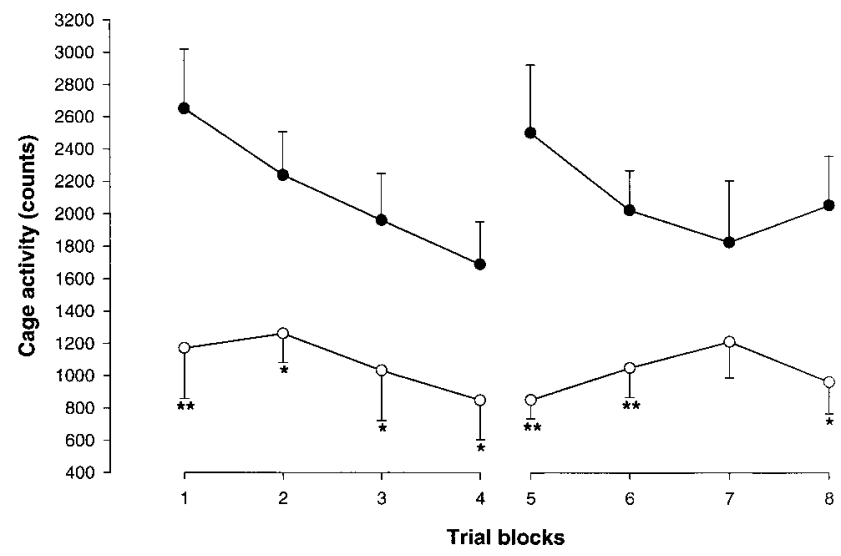

FIG. 5. Effect of pre-testing oral administration of CGP 40116 on cage activity. Symbols depict mean number of beam crossings $/ 2 \mathrm{~h}$ recording (and SEM). CGP 40116 consistently decreased cage activity recorded from 2 to $4 \mathrm{~h}$ after oral administration of $20 \mathrm{mg} / \mathrm{kg} \mathrm{CGP} 40116(n=8$ mice per group, open symbols) or water ( $n=7$, closed symbols). Drug administration schedules were similar to those used in the water maze task ( 8 trial days with CGP 40116 treatment; 3 days without drug administration between trial blocks 4 and 5). $* p<0.05$; $* * p<0.01$ vs. control group (Student's $t$-test). See text for statistical analysis.

Although we might have observed slightly improved learning ability in the $5 \mathrm{mg} / \mathrm{kg}$ treated animals (Fig. 4A), we could not find substantial evidence for such facilitation. Morris and co-workers were the first to show that chronic intraventricular infusion of a competitive NMDA antagonist could block LTP in vivo, and impair spatial learning in the hidden-platform water maze task, while acquisition in the visible-platform task remained unaffected $[4,34,35]$. It was suggested that this selectivity of the NMDA antagonist-induced impairment indicates that the effect of the antagonist on learning performance is through blockade of NMDA receptor-dependent synaptic plasticity, and not through some gross sensory-motor disturbance $[9,35]$.

In the acquisition of the hidden-platform water maze task, the mice will have to rely mainly on spatial localization strategies. In the visible-platform task, on the other hand, the animals learn to associate the escape platform with the presence of proximal cues. Visible-platform tasks are thus often used as the non-spatial control condition of this test [3]. However, our results in the visibletask probe trials indicate that the animals not only apply cue learning but also spatial search strategies, even when proximal cues are available. This spatial strategy enables them to show a preference for the target quadrant, and to enter the target area when neither the platform, nor the cue are present. This strategy, though apparently not as accurate as in the hidden-platform condition, was shown to be affected by CGP 40116 as well.

The results of Probe 1 indeed indicate that the antagonist affects the spatial component of the visible-platform task. When the drug-treated animals are trained longer, they improve significantly, and reach, in Probe 2, the same spatial accuracy as the control group, whereas the control animals did not show significantly improved spatial accuracy between Probe 1 and 2 . The improvement in the drug-treated group might have been a result of tolerance to the effects of the antagonist as tolerance to neuromotor effects of NMDA antagonists has been found in different administration protocols $[2,26,44]$. However, the neuromotor and passive avoidance results provide no evidence for the development of tolerance within the drug administration protocol applied here. Our findings suggest rather that the antagonist does not abolish the ability for spatial information acquisition altogether, but merely slows down the acquisition process. Slower acquisition rate is likely to explain the difference between control and drug-treated groups in the hidden-platform task also. In this condition, performance of the control group improved significantly between the two probe trials, whereas the difference between probe trial performances in the drug-treated mice was not statistically significant. Acquisition in this more complicated task may be longer than in the visible-platform condition, slowing of acquisition rate would have more profound effects, and this would explain why the effect of the drug is apparent also in Probe 2 of the hidden-platform task.

Cage activity, wire suspension, and rotarod tests were performed using a similar drug administration protocol as during the acquisition of the water maze task. Whereas the wire suspension was clearly impaired in the drug-treated animals, rotarod performance was not different between drug-treated and control animals, indicating that motor coordination and equilibrium were not affected by this kind of administration protocol. Although competitive and non-competitive NMDA antagonists have been shown to exert adverse neuromotor effects in various experimental paradigms, our observations suggest that muscular hypotonia is the main effect following oral administration of competitive NMDA antagonists. The persistent effect of orally administrated CGP 40116 on muscle strength or endurance could explain why swimming ability of CGP 40116-treated mice was impaired during 8 trial days of the water maze acquisition task. During the probe trials, which were performed $96 \mathrm{~h}$ after drug administration, these effects of the drug were absent. Cage activity was consistently suppressed by CGP 40116 administration. Other studies have reported hyper- as well as hypoactivity as a result of NMDA antagonist administration. Depending on the dose administered, hyperlocomotion or hypolocomotion and ataxia were observed in MK-801-treated kindled and normal rodents and CGP 37849 treated epileptic rats $[24,25,49]$. Starr and Starr [48], on the other hand, found no hyperactivity in CGP 40116-treated mice, and showed that the drug dose-dependently suppresses motor behavior in mice.

In this study, we have assessed the behavioural effects of oral administration of the potent competitive NMDA receptor antagonist CGP 40116 in mice. CGP 40116 dose-dependently impaired passive avoidance learning when given before, but not when given after training. The antagonist dose-dependently affected water maze acquisition, and impaired retention test performance in both hidden- and visible-platform water maze tasks. In addition, the drug had a dose-dependent effect on swimming speed during water maze acquisition. Repeated administration of CGP 40116 persistently decreased cage activity and wire suspension test performance, whereas motor coordination and equilibrium on the rotarod apparatus remained unimpaired. The present study shows that systemic administration of NMDA receptor antagonists induces both neuromotor- and memory-related impairments.

\section{ACKNOWLEDGEMENTS}

Financial support was obtained from Neurosearch Antwerp, OCMWAntwerp Medical Research Foundation, Born-Bunge Foundation, University of Antwerp and FGWO grant G.0027.97. Dr. Rudi D'Hooge is a postdoctoral fellow of the Belgian Fund for Scientific Research (FWOFlanders)

\section{REFERENCES}

1. Bane, A.; Rojas, D.; Indermaur, K.; Bennett, T.; Avery, D. Adverse effects of dextromethorphan on the spatial learning of rats in the Morris water maze. Eur. J. Pharmacol. 302:7-12; 1996. 
2. Boast, C. A.; Pastor, G.; Gerhardt, S. C.; Hall, N. R.; Liebman, J. M. Behavioral tolerance and sensitization to CGS 19755, a competitive N-methyl-D-aspartate receptor antagonist. J. Pharmacol. Exp. Ther. 247:556-561; 1988.

3. Brandeis, R.; Brandys, Y.; Yehuda, S. The use of the Morris water maze in the study of memory and learning. Int. J. Neurosci. 48:29-69; 1989.

4. Butcher, S. P.; Davis, S.; Morris, R. G. A dose-related impairment of spatial learning by the NMDA receptor antagonist, 2-amino-5-phosphonovalerate (AP5). Eur. Neuropsychopharmacol. 1:15-20; 1990.

5. Butelman, E. R. A novel NMDA antagonist, MK-801, impairs performance in a hippocampal-dependent spatial learning task. Pharmacol Biochem. Behav. 34:13-16; 1989.

6. Cain, D. P.; Saucier, D.; Boon, F. Testing hypotheses of spatial learning: the role of NMDA receptors and NMDA-mediated long-term potentiation. Behav. Brain Res. 84:179-193; 1997.

7. Chapman, A. G. Excitatory amino acid antagonists and therapy of epilepsy. In: Meldrum, B., ed. Excitatory amino acid antagonists. Oxford: Blackwell Scientific Publications UK; 1991:265-286.

8. Collingridge, G. L.; Watkins, J. C., eds. The NMDA receptor, 2nd ed. Oxford: Oxford University Press; 1994.

9. Cotman, C. W.; Iversen, L. L. Excitatory amino acids in the brainFocus on NMDA receptors. Trends Neurosci. 10:288-293; 1987.

10. Crawley, J.; Goodwin, F. K. Preliminary report of a simple animal behavior model for the anxiolytic effects of benzodiazepines. Pharmacol. Biochem. Behav. 13:167-170; 1980.

11. Danysz, W.; Wroblewski, J. T.; Costa, E. Learning impairment in rats by $\mathrm{N}$-methyl-D-aspartate receptor antagonists. Neuropharmacology 27:653-656; 1988.

12. Davis, S.; Butcher, S. P.; Morris, R. G. The NMDA receptor antagonist D-2-amino-5-phosphonopentanoate (D-AP5) impairs spatial learning and LTP in vivo at intracerebral concentrations comparable to those that block LTP in vitro. J. Neurosci. 12:21-34; 1992.

13. D'Hooge, R.; Raes, A.; Van Bogaert, P. P.; Geelhand, M.; De Deyn, P. P. Selective block of N-methyl-D-aspartic acid (NMDA)-evoked whole-cell currents in mouse cultured spinal neurones by CGP 40116 . Br. J. Pharmacol. 120:211-214; 1997.

14. D'Hooge, R.; Raes, A.; Hiramatsu, M.; Mori, A.; Van Bogaert, P.-P.; De Deyn, P. P. Effects of competitive N-methyl-D-aspartate antagonis CGP37849 and its ethylester CGP39551 on N-methyl-D-aspartateevoked whole-cell currents in cultured spinal neurones and on vestibular stimulation-induced seizures in EL mice. Arzneim.-Forsch./Drug Res. 48: 1121-1125; 1998.

15. Dunham, N. W.; Miya, T. S. A note on a simple apparatus for detecting neurological deficit in rats and mice. J. Am. Pharm. Assoc. 46:208209; 1957.

16. Fagg, G. E.; Olpe, H. R.; Pozza, M. F.; Baud, J.; Steinmann, M.; Schmutz, M.; Portet, C.; Baumann, P.; Thedinga, K.; Bittiger, H.; Allgeier, H.; Heckendorn, R.; Angst, C.; Brundish, D.; Dingwall, J. G. CGP 37849 and CGP 39551: Novel and potent competitive N-methylD-aspartate receptor antagonists with oral activity. Br. J. Pharmacol. 99:791-797; 1990.

17. Folbergrová, J. Anticonvulsant action of both NMDA and NonNMDA receptor antagonists against seizures induced by homocysteine in immature rats. Exp. Neurol. 145:442-450; 1997.

18. Fujikawa, D. G.; Daniels, A. H.; Kim, J. S. The competitive NMDA receptor antagonist CGP 40116 protects against status epilepticusinduced neuronal damage. Epilepsy Res. 17:207-219; 1994.

19. Gasior, M.; Borowicz, K.; Starownik, R.; Kleinrok, Z.; Czuczwar, S. J $\mathrm{Ca}^{2+}$ channel blockade and the antielectroshock activity of NMDA receptor antagonists, CGP 40116 and CGP 43487, in mice. Eur. J. Pharmacol. 312:27-33; 1996.

20. Goddard, G. V. A step nearer the neural substrate. Nature 319:721$722 ; 1986$

21. Gutnikov, S. A.; Gaffan, D. Systemic NMDA receptor antagonist CGP-40116 does not impair memory acquisition but protects against NMDA neurotoxicity in rhesus monkeys. J. Neurosci. 16:4041-4045; 1996.

22. Keith, J. R.; Rudy, J. W. Why NMDA-receptor-dependent long-term potentiation may not be a mechanism of learning and memory: Reappraisal of the NMDA-receptor blockade strategy. Psychobiology 18: 251-257; 1990.
23. Lederer, R.; Radeke, E.; Mondadori, C. Facilitation of social learning by treatment with an NMDA receptor antagonist. Behav. Neural Biol. 60:220-224; 1993.

24. Löscher, W.; Hönack, C. High doses of memantine induce seizures in kindled but not in non-kindled rats. Naunyn Schmiedeberg's Arch. Pharmacol. 341:476-481; 1990.

25. Löscher, W.; Hönack, C. Anticonvulsant and behavioural effects of two novel competitive N-methyl-D-aspartic acid receptor antagonists, CGP37849 and CGP39551, in the kindling model of epilepsy. Comparison with MK-801 and carbamazepine. J. Pharmacol. Exp. Ther. 256:432-440; 1991.

26. Lu, Y.; France, C. P.; Woods, J. H. Tolerance to the cataleptic effect of the N-methyl-D-aspartate (NMDA) receptor antagonists in pigeons: Cross-tolerance between PCP-like compounds and competitive NMDA antagonists. J. Pharmacol. Exp. Ther. 263:499-504; 1992.

27. Maier, C. M.; Sun, G. H.; Kunis, D. M.; Giffard, R. G.; Steinberg, G. K. Neuroprotection by the N-methyl-D-aspartate receptor antagonist CGP 40116: In vivo and in vitro studies. J. Neurochem. 65:652659; 1995.

28. Malenfant, S. A.; O'Hearn, S.; Fleming, A. S. MK801, an NMDA antagonist, blocks acquisition of a spatial task but does not block maternal experience effects. Physiol. Behav. 49:1129-1137; 1991.

29. Monaghan, D. T.; Olverman, H. J.; Nguyen, L.; Watkins, J. C.; Cotman, C. W. Two classes of N-methyl-D-aspartate recognition sites: differential distribution and differential regulation by glycine. Proc. Natl. Acad. Sci. USA 85:9836-9840; 1988.

30. Mondadori, C.; Weiskrantz, L.; Buerki, H.; Petschke, F.; Fagg, G. E. NMDA receptor antagonists can enhance or impair learning performance in animals. Exp. Brain Res. 75:449-456; 1989.

31. Mondadori, C.; Weiskrantz, L. Memory facilitation induced by $\mathrm{N}$ methyl-D-aspartate blockade. In: Baudry, M.; Davis, J. L., eds. Long term potentiation: A debate of current issues. Cambridge: MIT Press; 1991:259-266.

32. Mondadori, C.; Weiskrantz, L. NMDA receptor blockers facilitate and impair learning via different mechanisms. Behav. Neural Biol. 60: 205-210; 1993.

33. Mondadori, C.; Borkowski, J.; Gentsch, C. The memory-facilitating effects of the competitive NMDA-receptor antagonist CGP 37849 are steroid-sensitive, whereas its memory-impairing effects are not. Psychopharmacology (Berl.) 124:380-383; 1996.

34. Morris, R. G.; Garrud, P.; Rawlins, J. N.; O'Keefe, J. Place navigation impaired in rats with hippocampal lesions. Nature 297:681-683; 1982.

35. Morris, R. G.; Anderson, E.; Lynch, G. S.; Baudry, M. Selective impairment of learning and blockade of long-term potentiation by an N-methyl-D-aspartate receptor antagonist, AP5. Nature 319:774-776; 1986

36. Morris, R. G. Synaptic plasticity and learning: selective impairment of learning rats and blockade of long-term potentiation in vivo by the $\mathrm{N}$-methyl-D-aspartate receptor antagonist AP5. J. Neurosci. 9:30403057; 1989.

37. Morris, R. G.; Davis, M. The role of NMDA receptors in learning and memory. In: Collingridge, G. L.; Watkins, J. C., eds. The NMDA receptor, 2nd ed. Oxford: Oxford University Press; 1994:340-376.

38. Nellgård, B.; Wieloch, T. Cerebral protection by AMPA- and NMDAreceptor antagonists administered after severe insulin-induced hypoglycemia. Exp. Brain Res. 92:259-266; 1992.

39. Nellgård, B.; Wieloch, T. NMDA-receptor blockers but not NBQX, an AMPA-receptor antagonist, inhibit spreading depression in the rat brain. Acta Physiol. Scand. 146:497-503; 1992.

40. Nellgård, B.; Wieloch, T. Postischemic blockade of AMPA but not NMDA receptors mitigates neuronal damage in the rat brain following transient severe cerebral ischemia. J. Cereb. Blood Flow Metab. 12: $2-11 ; 1992$.

41. Okada, M.; Fujimura, Y.; Ueda, H.; Kometani, M.; Nakao, K.; Inukai, T. Effect of D-(E)-2-amino-4-methyl-5-phosphono-3-pentenoic acid on ischemic brain damage induced by four-vessel occlusion in rats. Arzneim.-Forsch./Drug Res. 47:115-119; 1997.

42. Papp, M.; Moryl, E. Antidepressant activity of non-competitive and competitive NMDA receptor antagonists in a chronic mild stress model of depression. Eur. J. Pharmacol. 263:1-7; 1994.

43. Pozza, M. F.; Olpe, H. R.; Brugger, F.; Fagg, G. E. Electrophysiological characterization of a novel potent and orally active NMDA recep- 
tor antagonist: CGP 37849 and its ethylester CGP 39551. Eur. J. Pharmacol. 182:91-100; 1990.

44. Rabbani, M.; Wright, E. J.; Little, H. J. Tolerance to competitive NMDA antagonists, but no crosstolerance with barbiturates. Pharmacol. Biochem. Behav. 50:9-15; 1995.

45. Sauer, D.; Allegrini, P. R.; Cosenti, A.; Pataki, A.; Amacker, H.; Fagg, G. E. Characterization of the cerebroprotective efficacy of the competitive NMDA receptor antagonist CGP 40116 in a rat model of focal cerebral ischemia: an in vivo magnetic resonance imaging study. J. Cereb. Blood Flow Metab. 13:595-602; 1993.

46. Sauer, D.; Allegrini, P. R.; Fagg, G. E. The competitive NMDA receptor antagonist CGP 40116 is a potent neuroprotectant in a rat model of focal cerebral ischemia. J. Neural Transm. Suppl. 43:81-89; 1994.

47. Schmutz, M.; Portet, C. H.; Jeker, A.; Klebs, K.; Vassout, A.; Allgeier, H.; Heckendorn, R.; Fagg, G. E.; Olpe, H.-R.; van Riezen, H. The competitive NMDA receptor antagonists CGP 37849 and CGP 39551 are potent, orally-active anticonvulsants in rodents. Naunyn Schmiedebergs Arch. Pharmacol. 342:61-66; 1990.

48. Starr, M. S.; Starr, B. S. The new competitive NMDA receptor antagonist CGP 40116 inhibits pilocarpine-induced limbic motor seizures and unconditioned motor behaviour in the mouse. Pharmacol. Biochem. Behav. 47:127-131; 1994.

49. Tricklebank, M. D.; Singh, L.; Oles, R. J.; Preston, C.; Iversen, S. D The behavioural effects of MK-801: A comparison with antagonists acting non-competitively and competitively at the NMDA receptor. Eur. J. Pharmacol. 167:127-135; 1989.

50. Venable, N.; Kelly, P. H. Effects of NMDA receptor antagonists on passive avoidance learning and retrieval in rats and mice. Psychopharmacology (Berl.) 100:215-221; 1990.

51. Ylinen, A.; Pitkanen, M.; Sirvio, J.; Hartikainen, T.; Sivenius, J.; Koivisto, E.; Riekkinen, P. J. The effects of NMDA receptor antagonists at anticonvulsive doses on the performance of rats in the water maze task. Eur. J. Pharmacol. 274:159-165; 1995. 